\title{
ARTD10/PARP10 Induces ADP-Ribosylation of GAPDH and Recruits GAPDH into Cytosolic Membrane-Free Cell Bodies When Overexpressed in Mammalian Cells
}

\author{
Emilia Mayo ${ }^{1, \dagger}$, Gaia Fabrizio ${ }^{1}$, Emanuele Salvatore Scarpa ${ }^{1}$, Annalisa Stilla ${ }^{1}$, Nadia Dani ${ }^{1, \dagger}$, \\ Fulvio Chiacchiera ${ }^{1,+}{ }^{-1 D}$, Henning Kleine ${ }^{2}$, Francesca Attanasio ${ }^{1}$, Bernhard Lüscher ${ }^{2}$ (D) \\ and Maria Di Girolamo ${ }^{1, *}$ \\ 1 G-Protein-mediated Signalling Laboratory, and Signal-Dependent Transcription Laboratory, Fondazione \\ Mario Negri Sud, Via Nazionale, 8/ A, 66030 Santa Maria Imbaro (CH), Italy; mayoemy@libero.it (E.M.); \\ gaiafabrizio@yahoo.it (G.F.); emanuele.scarpa@uniurb.it (E.S.S.); annalisa_stilla@yahoo.it (A.S.); \\ nadia.dani@bioclarma.com (N.D.); fulvio.chiacchiera@ieo.eu (F.C.); yattafrancy@tin.it (F.A.) \\ 2 Institute of Biochemistry and Molecular Biology, Medical School, RWTH Aachen University, \\ Pauwelsstraße 30, 52074 Aachen, Germany; hkleine@t-online.de (H.K.); luescher@rwth-aachen.de (B.L.) \\ * Correspondence: marielladigirolamo@hotmail.com; Tel.: +39-0872-570348; Fax: +39-0872-570412 \\ † Present Address: E.M.: Dompè, Via Castellino 111, 80131 Napoli, Italy. N.D.: Bioclarma srl, Via Nizza 52, \\ 10126 Torino, Italy. F.C.: European Institute of Oncology, Via Adamello 16, 20139 Milano, Italy.
}

Received: 22 February 2018; Accepted: 27 April 2018; Published: 3 May 2018

\begin{abstract}
Protein ADP-ribosylation is a reversible post-translational modification of cellular proteins that is catalysed by enzymes that transfer one (mono) or several (poly) units of ADP-ribose from $\beta-\mathrm{NAD}^{+}$to a specific amino acid of the target protein. The most studied member of the ADP-ribosyltransferase family is PARP1 (also known as ADP-ribosyltransferase diphtheria toxin-like 1, ARTD1), which is directly activated by DNA strand breaks and is involved in DNA damage repair, chromatin remodelling and transcriptional regulation. Much less is known about the further 16 members of this family. Among these, ARTD10/PARP10 has been previously characterised as a mono-ADP-ribosyltransferase with a role in cell proliferation and in NF-kB signalling. In the present study, we identified the glycolytic enzyme GAPDH as an interactor and a novel cellular target for ARTD10/PARP10. Moreover, we detected the co-localisation of GAPDH and ARTD10/PARP10 in well-defined cytosolic bodies, which we show here to be membrane-free, rounded structures using immunogold labelling and electron microscopy. Using the cognitive binding module macro domain to visualise ADP-ribosylated proteins by immunofluorescence microscopy in cells over-expressing the ARTD10/PARP10 enzyme, we show that the staining of the ARTD10/PARP10-dependent cytosolic bodies was lost when the cells were treated with compounds that inhibit ARTD10/PARP10, either by directly inhibiting the enzyme or by reducing the cellular $\mathrm{NAD}^{+}$levels. In parallel, the same treatment affected the co-localisation of GAPDH and ARTD10/PARP10, as GAPDH disappeared from the cytosolic cell bodies, which indicates that its presence there depends on the catalytic activity of ARTD10/PARP10. In line with this, in cells over-expressing the ARTD10/PARP10 catalytic domain alone, which we show here to form stress granules, GAPDH was recruited into stress granules. These data identify ARTD10/PARP10 as the enzyme that modifies and recruits GAPDH into cytosolic structures.
\end{abstract}

Keywords: ADP-ribosyltransferase; post-translational modification; mono-ADP-ribosylation; macro domain; GAPDH; cell proliferation; ARTD; ARTD10; NAD; apoptosis 


\section{Introduction}

ADP-ribosylation is a post-translational modification that is catalysed by ADP-ribosyltransferase (ART) enzymes. These ARTs transfer one (mono) or several (poly) units of ADP-ribose from $\beta$-NAD ${ }^{+}$ to specific amino acids of target proteins, thus regulating their functional properties [1-4]. The first ADP-ribosylating enzyme described in mammals was poly-ADP-ribose polymerase PARP1, a nuclear enzyme that is activated by DNA strand breaks and can synthesise linear or branched polymers of ADP-ribose that are comprised of up to 200 molecules of ADP-ribose linked together via O-glycosidic ribose-ribose bonds. PARP1 (also known as ART-diphtheria toxin-like 1, ARTD1) is the initial and most extensively studied member of the ARTD family, and it has a well-studied and recognised role in cellular responses to genotoxic and oxidative stress [5,6]. The ARTD family includes 17 human members [5,7], of which five other members, besides PARP1/ARTD1, are considered typical poly-ARTs: PARP2/ARTD2, PARP3/ARTD3, the vault PARP4/ARTD4, and the tankyrases PARP5a/ARTD5 and PARP5b/ARTD6; although more recently Vyas and collegues suggested that both ARP3/ARTD3 and the vault PARP4/ARTD4 can generate mono-ADPribose (8). Intriguingly, 11 members of this ARTD family have lost the conserved catalytic glutamate residue that is crucial for polymer elongation, and so these proteins are either inactive or are active mono-ARTs. These mono-ARTDs transfer a single ADP-ribose moiety from $\beta-\mathrm{NAD}^{+}$to a specific amino acid of their target proteins $[1-4,8,9]$. Many important intracellular proteins with key roles in cell signalling and membrane trafficking have been identified as targets of mono-ADP-ribosylation, including the endoplasmic reticulum (ER)-resident chaperone GRP78/BiP [10-13]; the heterotrimeric G-protein $\beta$ subunit [14-16]; the monomeric G-protein Arf6 [2,16]; the mitochondrial glutamate dehydrogenase [17,18]; two ER-associated ER stress sensors PERK and IRE1 $\alpha$ [19]; importin $\beta 1$ [20,21]; and glycogen synthase kinase $3 \beta$ (GSK3 $\beta$ ) [22].

The ARTs responsible for the modification of some of these proteins have not yet been identified, while others are known to be modified by a member of the ARTD family, similar to the ER stress sensors [19] and importin $\beta 1[20,21]$, which are modified by ARTD15/PARP16, and GSK3 ${ }^{\circledR}$, which is modified and thereby inhibited by ARTD10/PARP10 [23]. ARTD10/PARP10 is a $150 \mathrm{kDa}$ enzyme that comprises several domains of potential functional relevance, and it was the first ARTD to be characterised as a mono-ART [24]. In addition to the ART catalytic domain (aa 818-1025), the ARTD10 structure is characterised by an RNA recognition motif (RRM, aa 11-85) and a glycine-rich domain (aa 281-399) that are potentially involved in RNA binding; a glutamic acid (Glu)-rich region (aa 588-697) that contains two ubiquitin interaction motifs (UIM, aa 650-667 and 673-690); and a leucine-rich nuclear export sequence (NES; aa 598-607). ARTD10 is predominantly cytosolic under basal conditions, and it can shuttle between the cytoplasmic and the nuclear compartments. The NES mediates the nuclear export of ARTD10, while the region 408-649 appears to be involved in its nuclear import, despite the fact that ARTD10 does not have a clearly identifiable nuclear localization signal (NLS) [25]. ARTD10 was initially isolated as a partner of the oncoprotein c-Myc, and it was shown that its overexpression interferes with cell proliferation [24], although it remains unknown which protein(s) are mono-ADP-ribosylated by ARTD10 to mediate this growth inhibitory phenotype. A candidate here is GSK3 ${ }^{\circledR}$, which is known to regulate cell proliferation [26]. Once modified, in a reversible fashion, by ARTD10, the kinase activity of GSK $3{ }^{\circledR}$ is inhibited [22]. GSK $3{ }^{\circledR}$ is known to phosphorylate $\beta$-catenin, which is a modification that induces the proteasomal degradation of $\beta$-catenin [27], and thus ARTD10 might have a role in the Wnt/ $\beta$-catenin signalling pathway. ARTD10 is also a regulator of the NF-kB signalling pathway [28], which has a role in cell proliferation, in addition to its essential function in immune and inflammatory responses [29]. The NF-kB essential modulator (NEMO) is indeed mono-ADP-ribosylated by ARTD10. The intriguing model proposed by Verheugd and colleagues [28] shows that ARTD10, by means of its UIM motifs, binds K63-poly-ubiquitin chains that can be generated by tumour necrosis factor (TNF) receptor-associated factor (TRAF) proteins. Then, by ADP-ribosylating NEMO, ARTD10 inhibits NEMO K63-poly-ubiquitination and its downstream signal pathway, causing a reduced activation of NF-kB target genes. 
In the present work, we identified glyceraldehyde 3-phosphate dehydrogenase (GAPDH) as a novel substrate of ARTD10. GAPDH is a $37 \mathrm{kDa}$ glycolytic enzyme that catalyses the oxidative phosphorylation of glyceraldehyde 3-phosphate to 1,3-bisphosphoglycerate, using $\mathrm{NAD}^{+}$as a cofactor [30], and thus it controls the energy production pathway. This enzyme is tightly regulated at both transcriptional and posttranslational levels, and it is involved in diverse cellular functions that affect cell structure, gene expression, and signal transduction, thus linking metabolic activity to various cellular processes, including cell survival and proliferation [31,32]. It is well recognised that glucose metabolism has a central role in cell proliferation and carcinogenesis, and the majority of human tumours overexpress GAPDH. ADP-ribosylation is among the post-translational modifications that have been previously reported to regulate GAPDH activity. Indeed, GAPDH is already known as a substrate of poly-ADP-ribosylation by PARP1/ARTD1, which elicits large cellular energy deficits and accelerates cell death $[33,34]$. Moreover, GAPDH mono-ADP-ribosylation (on an arginine residue) in the spores of the fungus Phycomices blakesleeanus by an as-yet unidentified enzymatic activity, has been reported and hyphothesised to affect the energy metabolism and non-glycolytic functions of this fungus [35]. Finally, a modification of GAPDH that is induced by the fungal toxin brefeldin A (BFA) has also been reported [36,37], although its biological role remains to be defined.

Here, we show that ARTD10 can ADP-ribosylate GAPDH. Previous findings demonstrated that the expression of ARTD10, but not of its catalytically inactive mutant ARTD10-G888W, results in induction of apoptosis and inhibition of cell proliferation [38]. As ARTD10-G888W has no effects on apoptosis, it is likely that this pro-apoptotic effect is due to the mono-ADP-ribosylation of ARTD10 substrates [38]. Thus, the identification of novel ARTD10 substrates will be of help to define the biological functions of ARTD10.

\section{Material and Methods}

\subsection{Cell Culture, Transfections and Fractionation}

Chinese hamster ovary (CHO; ATCC, CCL-61) cells were grown as described previously [39]; cervical cancer HeLa (ATCC, CCL-2) cells were grown using modified Eagle's minimum essential medium (Invitrogen, Carlsbad, CA, USA) supplemented with $1 \%$ non-essential amino acids (Invitrogen); human bone osteosarcoma U2OS (ATCC, HTB-96) cells were grown using Dulbecco's modified Eagle's medium (Invitrogen); human promyelocytic leukemia cells (HL60; ATCC, CCL-240) were grown using Roswell Park Memorial Institute medium (RPMI 1640; Invitrogen). All growth media were supplemented with $2 \mathrm{mM}$ L-glutamine, $100 \mathrm{U} / \mathrm{mL}$ penicillin and $\mu \mathrm{g} / \mathrm{mL}$ streptomycin, and 10\% foetal calf serum, all from Invitrogen. Lipofectamine-Plus (Invitrogen) was used to transiently transfect the CHO cells, following the manufacturer's instructions. JetPEI (Polyplus) was used to transiently transfect the HeLa and U2OS cells, following the manufacturer's instructions. The cDNAs for the HA-ARTD10 wild-type (wt) and its mutant HA-ARTD10-G888W were generated as described previously [14].

Post-nuclear fractions were prepared from cells as follows. Confluent $\mathrm{CHO}$ cells $\left(3 \times 10^{7}\right.$ cells for each preparation) were washed twice with $5 \mathrm{~mL}$ Hank's Balanced Salt Solution (HBSS) without $\mathrm{Mg}^{2+}$ and $\mathrm{Ca}^{2+}$, detached in $0.25 \%$ trypsin solution, and pelleted at $200 \times \mathrm{g}$ for $5 \mathrm{~min}$. The pellets were resuspended in lysate buffer (RIPA buffer: $100 \mathrm{mM}$ Tris/ $\mathrm{HCl}, \mathrm{pH} 7.5 ; 1 \%$ Igepal; $0.5 \%$ deoxycholate; $0.1 \%$ SDS) at 500 cells $\mu \mathrm{L} /$ Petri dish, and then broken by passage (14 times) through a 25 -gauge syringe needle. Nuclei and unbroken cells were removed by centrifugation at $500 \times g$ for $15 \mathrm{~min}$, and the supernatant (post-nuclear fraction) was stored at $-80^{\circ} \mathrm{C}$ until use.

\subsection{ADP-Ribosylation Assays and GAPDH Activity Assay}

The ART activity was measured by following the incorporation of radioactive ADP-ribose into membrane components, as described previously [14]. When the ADP-ribosylation assay was performed with purified proteins, $500 \mathrm{ng}$ or $1 \mu \mathrm{g}$ purified recombinant ARTD10 and GAPDH proteins were 
incubated in $50 \mu \mathrm{L}$ ADP-ribosylation buffer (50 mM Potassium phosphate buffer (PFB), $\mathrm{pH}$ 7.4, $5 \mathrm{mM} \mathrm{MgCl}_{2}, 4 \mathrm{mM}$ dithiothreitol, $30 \mu \mathrm{M} \beta-\mathrm{NAD}^{+}$and $4.5 \mu \mathrm{Ci}\left[{ }^{32} \mathrm{P}\right]-\mathrm{NAD}^{+}$) for $60 \mathrm{~min}$ at $37^{\circ} \mathrm{C}$ ). Samples were separated by $10 \%$ SDS-PAGE and transferred to nitrocellulose filters (Perkin Elmer, Waltham, MA, USA). The filters were exposed to Kodak X-Omat film, using an intensifying screen, and quantified with an InstantImager (Packard Instrument Co., Thermo Fisher Scientific, Hampton, VA, USA). $N$-(6-Oxo-5,6-dihydro-phenanthridin-2-yl)- $N, N$-dimethylacetamide hydrochloride (PJ34) and meta-iodobenzylguanidine (MIBG) were purchased from Sigma Aldrich. The GAPDH activity was measured by evaluating the conversion of $\mathrm{NAD}^{+}$to NADH using the KDalert GAPDH assay kit (Ambion, Applied Biosystem, Foster City, CA, USA) in cells lysates prepared from either untransfected cells or cells transfected with ARTD10 wt or with catalytically inactive ARTD10-G888W.

\subsection{Western Blotting and Antibodies}

The cells were lysed and the protein concentrations were determined using the Bio-Rad protein assay (Bio-Rad, Hercules, CA, USA). Samples were separated using 10\% SDS-PAGE, and transferred onto nitrocellulose filters (Perkin Elmer, Waltham, MA, USA). The Western blots were incubated with primary antibodies diluted in T-TBS for $1 \mathrm{~h}$ at room temperature, or overnight at $4{ }^{\circ} \mathrm{C}$. After washes with T-TBS, the Western blots were incubated with horseradish-peroxidase-conjugated secondary anti-mouse or anti-rabbit antibodies (Calbiochem, Merck, Kenilworth, UK). Protein bands were visualised with the ECL-plus chemiluminescence reagent (GE Healthcare, Little Chalfont, UK), according to manufacturer instructions. The following primary antibodies were used: monoclonal antibody raised against ARTD10, a monoclonal anti-HA from Covance, and a monoclonal anti-GAPDH from Santa Cruz Biotechnology.

\subsection{Co-Immunoprecipitation, Immunoprecipitation, and GST-Pull Down}

Semi-confluent HL60 cells $\left(1 \mathrm{~mL} / 10 \times 10^{4}\right.$ cells) were centrifuged for $5 \mathrm{~min}$ at $200 \times g$ and incubated with RIPA buffer, for $30 \mathrm{~min}$ at $4{ }^{\circ} \mathrm{C}$, with constant rotation. For immunoprecipitation, semi-confluent $\mathrm{CHO}$ and HeLa cells were transiently transfected with the empty vector or with the indicated HA-ARTD enzymes, and then incubated with RIPA buffer $(1 \mathrm{~mL} / 100 \mathrm{~mm}$ Petri dish). The cells were broken by passage (14 times) through a 25-gauge syringe needle. The lysates were collected and centrifuged at $12,000 \times g$ for $45 \mathrm{~min}$ at $4{ }^{\circ} \mathrm{C}$. The supernatants were incubated with $2 \mu \mathrm{g}$ anti-ARTD10 or anti-GAPDH antibodies (co-immunoprecipitation; Figure 1E), or with $2 \mu \mathrm{g}$ anti-HA antibody (immunoprecipitation; Figure 1C) overnight at $4{ }^{\circ} \mathrm{C}$, with constant shaking. The day after, the samples were incubated with $40 \mu \mathrm{g}$ of a $50 \%$ slurry of protein-A Sepharose resin (CL4B; Amersham Pharmacia Biotech, GE Healthcare, Little Chalfont, UK), for $1 \mathrm{~h}$ at $4{ }^{\circ} \mathrm{C}$, with constant rotation $(200 \mathrm{rpm})$. The resin was washed three times with RIPA buffer, and then boiled in loading buffer. The samples were either analysed by silver staining, and the immunoprecipitated bands were identified by MALDI-TOF mass spectrometry (immunoprecipitation; Figure 1C) or resolved by Western blotting using antibodies raised against GAPDH or the HA tag. The GST pull-down was performed as previously reported [13,40]. Briefly, two mg of total lysates for each sample were solubilised with $1.5 \mathrm{~mL}$ RIPA buffer and incubated with a glutathione-Sepharose resin for $2 \mathrm{~h}$ at $4{ }^{\circ} \mathrm{C}$, for the preclearing step. The supernatant underwent two-steps of pull-down, the first with $50 \mu \mathrm{g}$ macro domain (m)Af1521/G42E mutant, covalently cross-linked to a resin, which does not recognise ADP-ribosylated proteins, for $4-5 \mathrm{~h}$ at $4{ }^{\circ} \mathrm{C}$. The supernatant from the first pull-down was then incubated overnight at $4{ }^{\circ} \mathrm{C}$ with $50 \mu$ g GST-tagged $m$ Af1521 wt. The beads were collected by centrifugation at $700 \times g$ for $5 \mathrm{~min}$, and washed three times with $1 \mathrm{~mL}$ lysis buffer. Protein that remained bound to the resin was eluted at $100{ }^{\circ} \mathrm{C}$ for $5 \mathrm{~min}$ with sample buffer, and then subjected to SDS-PAGE. The eluted proteins analysed by gels underwent silver staining, and the bands of interest were cut, trypsinised and analysed by MALDI-TOF mass spectrometry. 
A

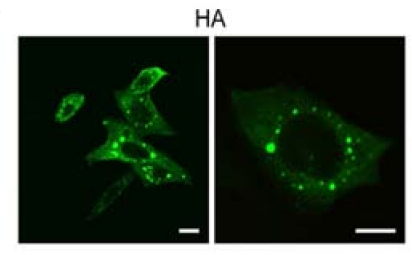

B

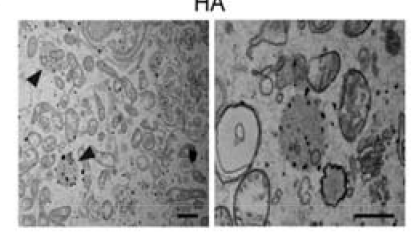

D

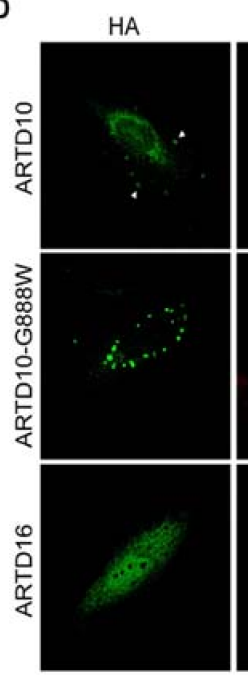

GAPDH
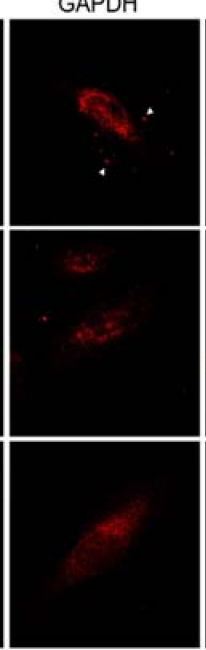

Flag

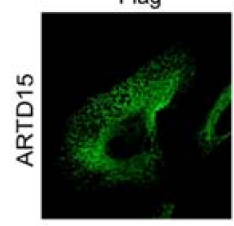

GAPDH

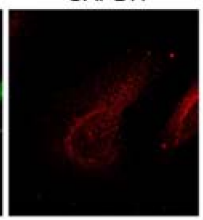

Merge
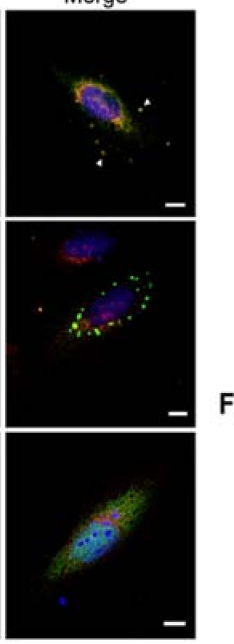

Merge

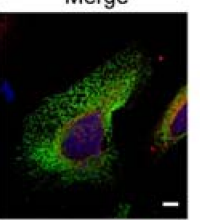

C

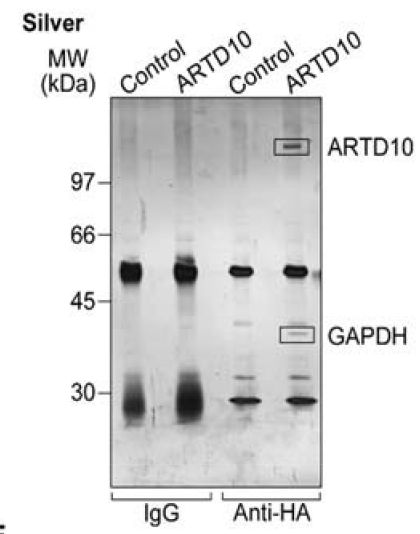

WB
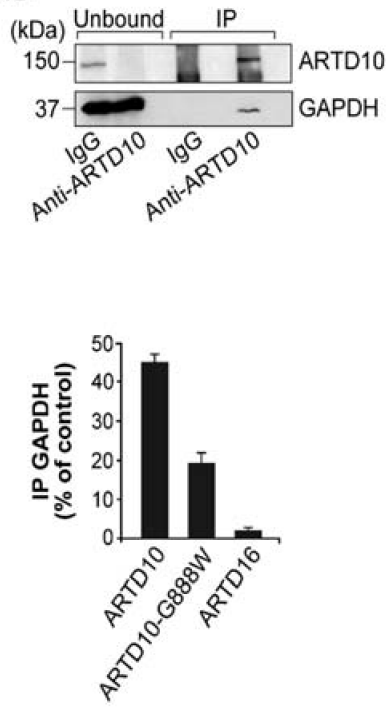

Figure 1. ARTD10/PARP10 interacts with GAPDH. (A) Representative immunofluorescence staining of ARTD10 (green) in CHO cells transiently transfected with HA-ARTD10; (B) Representative electron microscopy of immuno-gold staining of ARTD10 (black dots, indicated by arrows) in CHO cells overexpressing ARTD10 wt. (A,B) The two panels show two different samples with images taken with different magnifications. Data are representative of at least four different experiments; (C) Representative analysis of lysates ( $2 \mathrm{mg}$ protein) from $\mathrm{CHO}$ cells transfected with empty vector (control) or HA-ARTD10 were immunoprecipitaed with an anti-HA (Hemagglutinin) antibody. Proteins were separated by $10 \%$ SDS-PAGE and revealed by silver staining. Differentially immunoprecipitated proteins were excised from gels and identified by MALDI-TOF mass spectrometry (boxed bands) as ARTD10 and GAPDH; (D) Representative immunofluorescence of HeLa cells transiently transfected with the indicated HA-tagged ARTD enzymes or with the FLAG-tagged ARTD15, stained with anti-HA (HA; green) or anti-FLAG (FLAG; green) and anti-GAPDH (GAPDH: red) antibodies. Cells transfected with the ARTD10-G888W mutant, as compared to cells transfected with wt protein, tend to form larger cell-bodies. (C,D) Data are representative of three independent experiments. Scale bars, $10 \mu \mathrm{m}$ (A,D), $0.3 \mu \mathrm{m}$ (B); (E) Representative co-immunoprecipitation of endogenous ARTD10 and GAPDH in HL60 cell total lysates. Western blotting (WB) was performed using an anti-GAPDH antibody; (F) Quantification of GAPDH immunoprecipitation in HeLa cells transiently transfected with the indicated HA-tagged ARTD enzymes. (E,F) Data are representative of two independent experiments. MW $=$ Molecular Weight . 


\subsection{Proteomic Analysis}

Protein spots were manually excised from gels and digested with porcine trypsin (Promega, Madison, WI, USA), and the peptide mixture obtained was treated and eluted off of ZipTips C18 (Millipore, Billerica, MA, USA) according to the manufacturer's instructions and then directly deposited onto MALDI target plates with a matrix ( $\alpha$-cyano-4-hydroxycinnamic acid) solution ( $50 \%$ acetonitrile $/ 0.1 \%$ trifluoroacetic acid, at saturation concentration). The MALDI-TOF spectra in the $700 \mathrm{Da}$ to $4000 \mathrm{Da} m / z$ range were acquired on a Reflex IV mass spectrometer (Bruker Daltonics, Bremen, Germany) in reflector mode. All of the mass spectra were calibrated with a peptide mixture composed of angiotensin I, Glu-fibrinopeptide, renin, bradykinin, and adrenocorticotropic hormone. Peak lists from the mass spectra were obtained with the flexAnalysis 3.0 software (Bruker Daltonics), with trypsin autolysis peaks, matrix cluster ions, and eventual masses of tryptic peptides from keratin were excluded manually from the peak list. To this end, as a control, for each set of analyses, a mass spectrum of a gel fragment cut from outside the proteins separation area was also analysed. Protein identification was performed by searching for human proteins in the non-redundant NCBI database, using the BioTool 3.0 software (Bruker Daltonics) integrated with the Mascot search engine (Matrix Science, http:/ / www.matrixscience.com/, London, UK), with the following search criteria: carbamidomethylation of cysteine as a fixed modification, and methionine oxidation as a variable modification, monoisotopic mass, peptide tolerance 100-200 ppm, porcine trypsin as a specific enzyme and 1 missed cleavage.

\subsection{Indirect Immunofluorescence and Antibodies}

HeLa, U2OS, CHO cells $\left(2 \times 10^{4}\right)$ were transiently transfected on glass coverslips in 24-well plates. Twenty-four hours after transfection, the cells were washed with phosphate-buffered saline (PBS), fixed for $10 \mathrm{~min}$ at room temperature with $4 \%$ paraformaldehyde, permeabilised in blocking solution (PBS, $50 \mathrm{mM} \mathrm{NH}_{4} \mathrm{Cl}, 0.5 \% \mathrm{BSA}, 0.1 \%$ saponin) for $20 \mathrm{~min}$ at room temperature, and stained with an anti-HA antibody (Cell Signalling Technology, Leiden, The Netherlands; 1:600 in blocking solution) and an anti-GAPDH antibody (Santa Cruz Biotechnology, Dallas, TX, USA; 1:50 in blocking solution). The GST-mAf1521 immunofluorescence staining was performed as described [13]. Briefly, the cells were fixed, permeabilised and then incubated for $1 \mathrm{~h}$ at room temperature with $6 \mathrm{ng}$ of GST- $m$ Af1521. The cells were then washed with PBS, and the ADP-ribosylated proteins were detected with the rabbit anti-GST antibody (1:1000 in blocking solution). Alexa 488- and Alexa 546-conjugated goat anti-rabbit and anti-mouse IgG (Molecular Probes, Thermo Fisher Scientific, Hampton, VA, USA; 1:400 in blocking solution) were used as secondary antibodies; DRAQ5 (Cell Signaling Technology, Leiden, The Netherlands; 1:1000 in blocking solution) was used to stain nuclei. The samples were analysed under a confocal microscope (Zeiss LSM 510; Zeiss, Thornwood, NY, USA). Paraformaldehyde and saponin were from Sigma-Aldrich, St. Louis, MO, USA. Mowiol was from Calbiochem, Merck, Kenilworth, UK. FK866 was from Selleckchem, Houston, TX, USA. Transfected cells treated with FK866 were incubated for $24 \mathrm{~h}$ with $10 \mathrm{nM}$ FK866. The co-localization analysis of ARTD10 enzymes with GAPDH in the cells was performed with LSM510-3.2 software (Zeiss). To assess the co-localization, we removed the background immunofluorescence by adjusting the threshold levels and used the histo and co-localization functions of the above software. This software provides two co-localization coefficients that range from 0 (no co-localization) to 1 (complete co-localization). The co-localization coefficients indicate the number of pixels of channel A that co-localize with pixels from channel B and vice versa. We expressed the co-localization extent as a percentage over the total immunofluorescence per channel.

\subsection{Electron Microscopy}

CHO cells $\left(2 \times 10^{4}\right)$ were transiently transfected with HA-ARTD10 wt in Petri dishes with CELLocate grided coverslips (MatTek Corporation, Ashland, MA, USA) and then used for immuno-electron 
microscopy analysis using the gold-enhance protocol [41], as described previously [42]. Briefly, the cells were collected in a $1.5 \mathrm{~mL}$ tube and fixed first with a mixture of $0.05 \%$ glutaraldehyde and $4 \%$ paraformaldehyde in 0.2 M HEPES (4-(2-hydroxyethyl)-1-piperazineethane sulfonic acid) for $10 \mathrm{~min}$ at room temperature, and then with $4 \%$ paraformaldehyde in 0.2 M HEPES for $30 \mathrm{~min}$ at room temperature. Next, the cells were permeabilised with blocking solution for $30 \mathrm{~min}$ and incubated overnight with an anti-HA antibody (1:100 in blocking solution) at $4{ }^{\circ} \mathrm{C}$. The day after, the cells were washed three times with PBS and incubated with nanogold-conjugated anti-mouse IgG (NanoProbes, Yaphank, NY, USA; 1:100 in blocking solution) for $2 \mathrm{~h}$ at room temperature. According to the manufacturer's instructions, the formation of larger gold particles was induced, using the GoldEnhancement reaction (NanoProbes, Yaphank, NY, USA). The cells were washed and post-fixed with $2 \% \mathrm{OsO}_{4}$ and $3 \%$ potassium ferrocyanide for $1 \mathrm{~h}$ at room temperature, and then the samples were dehydrated in the series of 50\%,70\%, 90\% and 100\% ethanol, for $10 \mathrm{~min}$ at room temperature of each. Finally, the cells were embedded in Epon resin and incubated at $60{ }^{\circ} \mathrm{C}$ in the oven for $24 \mathrm{~h}$. Electron microscopy images were acquired using a Philips Tecnai-12 electron microscope at $120 \mathrm{~kW}$ (FEI/Philips Electron Optics, Eindhoven, The Netherlands) with an ULTRA VIEW CCD digital camera. Glutaraldehyde, Epon and $\mathrm{OsO}_{4}$ were from Sigma-Aldrich.

\subsection{Statistical Analysis}

Data are expressed as means \pm standard deviation. Unpaired Student's $t$-tests were performed on the means, and the $p$ values were calculated using the GraphPad PRISM software version 4.0b. A $p<0.05$ was considered statistically significant. For the co-localization analysis, values are expressed as means \pm standard error of the mean (SEM) and analyzed by one-way analysis of variance (ANOVA), calculated using GraphPad PRISM software version $4.0 \mathrm{~b}$. A $p<0.05$ was considered significant.

\section{Results and Discussion}

\subsection{ARTD10 Localises in Membrane-Free Cell Bodies}

ARTD10 is predominantly cytosolic under basal conditions and forms discrete and dynamic 'bodies' in the cytoplasm [25]. In the present study, we first confirmed the cellular localisation of ARTD10, and then we extended our search to its target proteins. To this end, we analysed $\mathrm{CHO}$ cells transfected with HA-tagged ARTD10 (HA-ARTD10) using immunofluorescence microscopy (Figure 1A) and immuno-electron microscopy (Figure 1B). Immunofluorescence images confirmed the ARTD10 staining in well-defined cytosolic bodies (Figure 1A), while there was no detectable HA staining in mock-transfected cells (shown in Figures 3-6; Control-HA). Immunogold labelling and electron microscopy showed that ARTD10 localises to rounded bodies, and of note, this highlighted that these bodies contain dense material and lack surrounding membranes (Figure 1B). It has been previously shown that these ARTD10-associated bodies are not P-bodies or stress granules and represent dynamic structures that can move considerable distances and tend to fuse over time, while also forming de novo, and disappearing [24]. Further to this characterisation, and although we now show that these ARTD10-associated bodies are rounded membrane-free structures, their biological meaning remains to be understood.

\subsection{ARTD10 Interacts and Co-Localises with GAPDH in Membrane-Free Cell Bodies}

To investigate the biological role of these ARTD10-dependent bodies, and reasoning that it was not possible to isolate these dynamic structures considering that they are membrane-free, we searched for ARTD10 interactors in CHO cells overexpressing HA-ARTD10 (Figure 1C). To this end, total lysates were prepared from $\mathrm{CHO}$ cells that had been transiently transfected with either cDNA encoding for HA-ARTD10 or the corresponding empty vector (Control), which were then analysed in immunoprecipitation experiments using either an anti-HA antibody or control IgG. Figure 1C shows that two bands were specifically immunoprecipitated from HA-ARTD10 cells, as revealed by silver 
staining. These bands were identified by MALDI-TOF-MS analysis as ARTD10 itself and the glycolytic enzyme GAPDH (Figure 1C), which demonstrated that GAPDH is an ARTD10 interactor in intact cells. As a further control, no peptide matching with ARTD10 and GAPDH was found in the gel locations corresponding to ARTD10 and GAPDH of the Control sample. We then evaluated the co-localisation of ARTD10 and GAPDH by immunofluorescence microscopy and validated the interaction between these two proteins by co-immunoprecipitation. The immunofluorescence of HA-ARTD10 CHO cells showed that ARTD10 and endogenous GAPDH co-localised into the cytoplasmic cell bodies (Figure 1D), which suggested that when ARTD10 forms these bodies, endogenous GAPDH can be recruited to them. The quantification of the immunufluorescence analysis (see methods) indicates that $45 \% \pm 2 \%$ of GAPDH co-localised with ARTD10-foci in ARTD10-transfected cells, while only $19 \% \pm 3 \%$ of GAPDH co-localises with catalytically inactive ARTD10-foci. Then, we evaluated the interactions of the endogenous proteins using HL60 cells, as it was previously shown that these cells express appreciable amounts of endogenous ARTD10 [24]. Total lysates from HL60 cells were subjected to immunoprecipitation using an anti-ARTD10 antibody (Figure 1E). Under these conditions, GAPDH was co-immunoprecipitated with endogenous ARTD10, as revealed by Western blotting using an anti-GAPDH antibody (Figure 1E). Finally, we evaluated the level of co-immunoprecipitated GAPDH from cells transfected with either HA-ARTD10 wt, or its inactive mutant HA-ARTD10-G888W [43], or with a different HA-tagged enzyme (HA-ARTD16). HA-ARTD16 was used as a further control considering that this enzyme does not form foci and does not co-localise with GAPDH (Figure 1D; ARTD16), similar to the endoplasmic reticulum-associated FLAG-ARTD15 [43] (Figure 1D; ARTD15). The quantification of the immunoprecipitated GAPDH (Figure 1F) indicates that the catalytically inactive HA-ARTD10-G888W [43] can bind GAPDH, although to a lower extent compared to the catalytically active enzyme. Moreover, no detectable GAPDH was co-immunoprecipitated by HA-ARTD16, in line with the immunofluorescence. Taken together, co-immunoprecipitation experiments indicated that ARTD10 and GAPDH can interact and they are part of the same complex.

\subsection{ARTD10 Catalyses Mono-ADP-Ribosylation of GAPDH}

The finding that ARTD10 and GAPDH are interacting partners prompted us to investigate whether GAPDH can be ADP-ribosylated by ARTD10. With this aim, we initially evaluated whether GAPDH can be pulled-down by the GST-tagged 'macro' domain module (GST-mAf1521), which we have shown can be used as selective bait for high-affinity purification of mono-ADP-ribosylated proteins [40]. This was done using cells transfected with the catalytically active ARTD10 (Figure 2A), and then we used the recombinant proteins to further analyse whether ARTD10 can catalyse GAPDH ADP-ribosylation, and whether these two proteins can interact directly (Figure 2B). CHO cells were either not transfected or were transfected with HA-ARTD10 wt or with its inactive mutant HA-ARTD10-G888W [43]. Cell lysates were subjected to two-step pull-down with GST-tagged $m$ Af1521 [40]. The first pull-down was performed using the GST-tagged $m$ Af1521/G42E mutant, which does not bind ADP-ribosylated proteins. Then, the unbound material underwent a second pull-down with GST- $m$ Af1521 wt, to specifically retain ADP-ribosylated proteins [40]. A band of ca. $37 \mathrm{kDa}$ was detected in the HA-ARTD10-transfected CHO cells and was identified by MALDI-TOF mass spectrometry as GAPDH (Figure 2A). No band corresponding to GAPDH was detected when the same pull-down assay was performed with cells transfected with the empty vector alone (Figure 2A, Control) or with the inactive HA-ARTD10-G888W (Figure 2A). These data suggested that GAPDH can be ADP-ribosylated by ARTD10; however, at this stage, we cannot exclude that GAPDH can be pulled down due to its interaction with another ADP-ribosylated protein, including ARTD10 itself. For this reason, we evaluated the enzymatic activity of ARTD10 towards GAPDH using the recombinant proteins in an in-vitro ADP-ribosylation assay. Purified GAPDH was incubated with either ARTD10 (Figure 2B,C) or with its catalytically inactive counterpart ARTD10-G888W (Figure 2B) in the presence of $\left[{ }^{32} \mathrm{P}\right]-\mathrm{NAD}^{+}$. The autoradiography (Figure 2B, AR) showed that GAPDH was specifically labelled only when incubated with catalytically active recombinant ARTD10. Moreover, under these 
experimental conditions, ARTD10 was more active than PARP1 in modifying GAPDH, while other ARTD enzymes, including ARTD15 and ARTD16, did not modify GAPDH (data not shown).

A

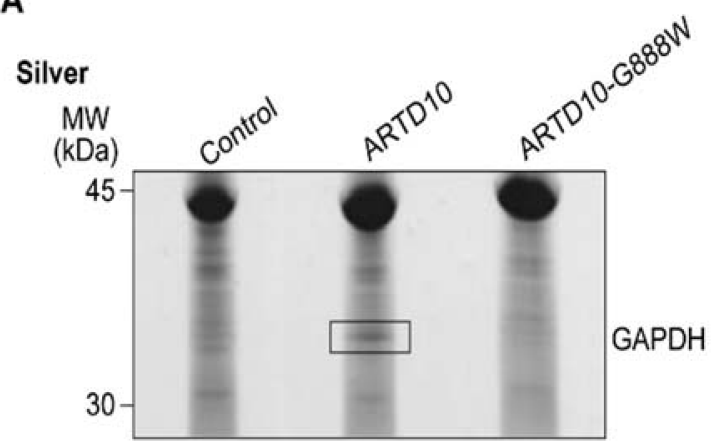

C

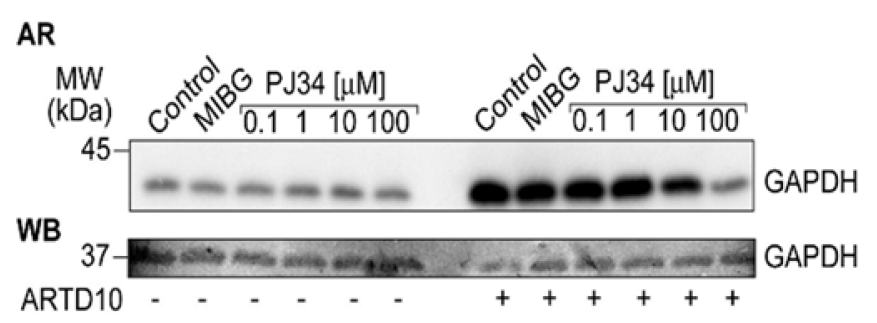

B

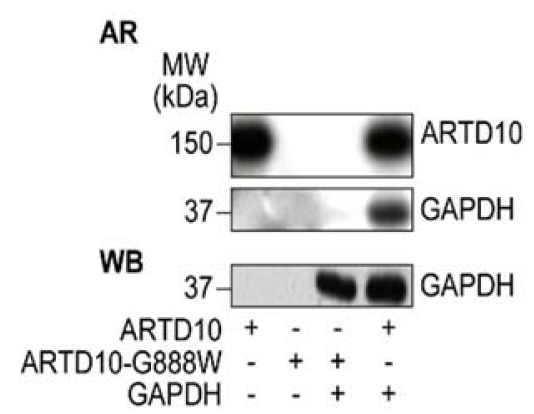

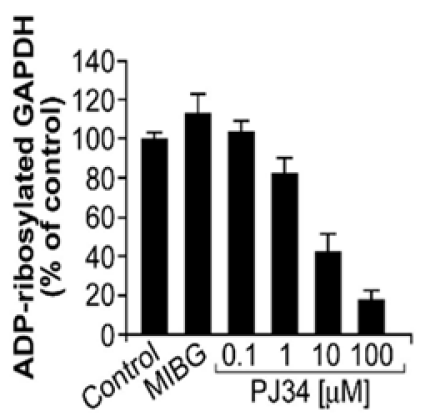

Figure 2. ARTD10/PARP10 ADP-ribosylates GAPDH. (A) Representative pull-down assay from $\mathrm{CHO}$ cells transfected with an empty vector (control) or with HA-tagged ARTD10 or ARTD10-G888W. Cell lysates (2 mg protein) underwent a non-specific pull-down step using the GST-tagged $m$ Af1521/G42E mutant (with abrogated binding of $m$ Af1521 ADP-ribosylated proteins). The unbound material underwent a second pull-down with GST-mAf1521 wt, to specifically retain ADP-ribosylated proteins. This two-step procedure resulted in separation of specific proteins that were revealed by colloidal Coomassie blue staining and identified by MALDI-TOF analysis; (B) GAPDH was $\left[{ }^{32} \mathrm{P}\right]-\mathrm{ADP}$-ribosylated in vitro for $1 \mathrm{~h}$ at $37{ }^{\circ} \mathrm{C}$ in the presence of ARTD10 or ARTD10-G888W, separated by SDS-PAGE, and analysed by autoradiography (AR). Recombinant GAPDH is shown by immunoblotting with an anti-GAPDH antibody. The data shown are representative of four independent experiments; (C) GAPDH was [ $\left.{ }^{32} \mathrm{P}\right]$-ADP-ribosylated in vitro for $1 \mathrm{~h}$ at $37^{\circ} \mathrm{C}$ in the presence of ARTD10 and MIBG $(200 \mu \mathrm{M})$ or increasing concentrations of PJ34 $(0.1-100 \mu \mathrm{M})$, separated by SDS-PAGE, and analysed by autoradiography (AR). Recombinant GAPDH is shown by immunoblotting with an anti-GAPDH antibody. Quantification of these representative data of ARTD10-mediated ADP-ribosylated GAPDH (as \% modified protein) upon treatment with these inhibitors is shown on the right, with the data expressed as means $\pm \mathrm{SD}$ from three independent experiments.

ARTD10-mediated GAPDH ADP-ribosylation was further investigated by making use of ADP-ribosylation inhibitors. Specifically, we used compounds previously characterised for their ability to specifically inhibit different families of the ART enzymes. We tested the arginine-specific mono-ART inhibitor MIBG [44], and the well-characterised inhibitor of the ARTD enzymes, PJ34 [45], using the in-vitro ADP-ribosylation assays with the purified proteins. MIBG $(200 \mu \mathrm{M})$ was ineffective for inhibition of the ARTD10-[ $\left.{ }^{32} \mathrm{P}\right]-\mathrm{ADP}$-ribosylation of GAPDH, while increasing concentrations of PJ34 $(0.1-100 \mu \mathrm{M})$ inhibited ARTD10-[32 P]-ADP-ribosylation of GAPDH in a dose-dependent manner (Figure 2C), confirming that even if PJ34 is not a specific ARTD10 inhibitor, a high concentration of this compound is effective [45]. Altogether, these data confirm that ARTD10 and GAPDH interact, and that GAPDH is specifically ADP-ribosylated by ARTD10. 
We then evaluated whether the ARTD10-mediated ADP-ribosylation of GAPDH could regulate the dehydrogenase activity of GAPDH. CHO cell lysates, prepared from cells either non-transfected or transfected with HA-ARTD10 wt or with its inactive mutant HA-ARTD10-G888W, were analysed for GAPDH activity (see Methods). Similar levels of GAPDH activity were measured in all samples (Supplementary Figure S1), thus indicating that the dehydrogenase activity of GAPDH is not regulated by its ADP-ribosylation and supporting the hypothesis that ADP-ribosylation is required for the recruitment of GAPDH into cell bodies.

\section{4. mAf1521 Allows Visualisation of the ARTD10 Membrane-Free Cell Bodies}

As we showed that ARTD10 and GAPDH co-localise in the cytoplasmic cell bodies (Figure 1D), and that GAPDH is ADP-ribosylated by ARTD10 (Figure 2), we used the cognitive binding module mAf1521 to visualise the intracellular localisation of ADP-ribosylated proteins in HeLa cells by immunofluorescence microscopy [45] (Figure 3). The HeLa cells were either not transfected (mock; Figure 3, control) or were transfected with the HA-ARTD10 wt (Figure 3, ARTD10) or with its inactive mutant HA-ARTD10-G888W (Figure 3, ARTD10-G888W), incubated with GST-mAf1521 and then analysed by immunofluorescence microscopy, using an anti-HA antibody to detect the overexpressed enzymes, and an anti-GST antibody to visualise ADP-ribosylation. The immunofluorescence images showed clear cytosolic cell body staining for ARTD10 (Figure 3, ARTD10) and for ARTD10-G888W (Figure 3, ARTD10-G888W). Of note, the staining with GST-mAf1521 revealed ARTD10-containing cell bodies stained in cells transfected with enzymatically active ARTD10; in contrast, in the cells transfected with the inactive protein, ARTD10-G888W, there was no cell-body staining with GST-mAf1521, which instead showed a punctate, nuclear staining, as in the control cells. The mutated GST-mAf1521/G42E that cannot bind ADP-ribosylated proteins showed no staining in the control and transfected cells (not shown), as expected [45]. This staining with GST-mAf1521 in cells transfected with enzymatically active ARTD10 is in line with ADP-ribosylation events occurring at the level of the ARTD10-containing cell bodies, although it is not possible to discriminate whether the staining is associated with either ARTD10 or GAPDH, or both. Furthermore, the prominent GST-mAf1521-dependent change in the staining of cells seen upon transfection with the active ARTD10 enzyme was completely abolished when the cells were treated with either PJ34 $(50 \mu \mathrm{M}$; Figure 3, ARTD10 + PJ34), which inhibits ARTD10-dependent ADP-ribosylation of GAPDH (Figure 2C), or with FK866 (10 $\mu$ M; Figure 3, ARTD10 + FK866), which inhibits Nampt (a key enzyme involved in $\mathrm{NAD}^{+}$biosynthesis) and thus reduces the $\mathrm{NAD}^{+}$levels in cells $[45,46]$. Thus, these data in addition to confirming that ADP-ribosylation events occur in cell bodies containing the over-expressed ARTD10 [46] also demonstrate that the inhibition of the ART activity of ARTD10 by PJ34 and the decreased levels of NAD ${ }^{+}$(the cofactor of the ADP-ribosylation reaction) by FK866 resulted in the disappearance of ADP-ribosylated proteins from the cytoplasmic bodies. These last results are in line with the concept that the catalytic activity of ARTD10 is not strictly required for the formation of these cell bodies; indeed, other domains of the ARTD10 protein have been demonstrated to be required for formation of cell bodies [46], although ADP-ribosylation/de-ribosylation events can occur within these cell bodies and might have a role in the recruitment of ARTD10 targets. 


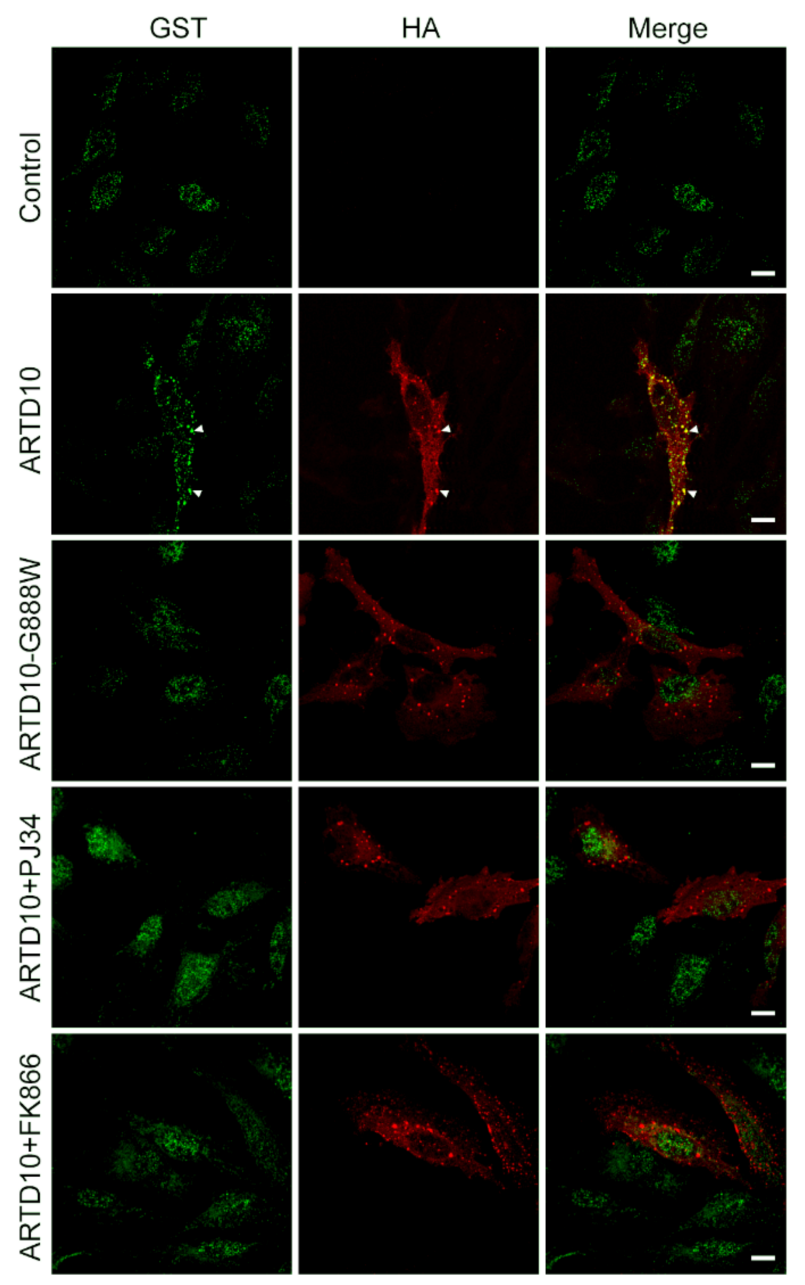

Figure 3. ARTD10/PARP10-cytoplasmic cell bodies are specifically recognised by the Af1521 wt macro domain. Representative immunofluorescence microscopy of HeLa cells that were mock-transfected (Control) or were transiently transfected with ARTD10, ARTD10-G888W, or ARTD10 with treatment with PJ34 (ARTD10 + PJ34) or with FK866 (ARTD10 + FK866). The cells were incubated with GST-mAf1521 wt, stained with anti-Glutathione S-Transferase (GST) (GST; green) and anti-HA (HA; red) antibodies, and analysed by immunofluorescence microscopy. Scale bars, $10 \mu \mathrm{m}$. Data are representative of at least three independent experiments.

\subsection{ARTD10-Dependent GAPDH Localisation in Membrane-Free Cell Bodies}

To support the hypothesis that ADP-ribosylation is crucial for the recruitment of GAPDH into these cell bodies, we further investigated the co-localisation of GAPDH with the active and inactive ARTD10 proteins in HeLa and U2OS cancer cell lines. HeLa (Figure 4) and U2OS (Figure 5) cells were either not transfected (mock, control) or were transfected with HA-ARTD10 wt or with its inactive mutant HA-ARTD10-G888W, incubated with FK866 (where indicated), and then analysed by immunofluorescence microscopy using an anti-HA antibody to detect the overexpressed enzymes, and an anti-GAPDH antibody. The immunofluorescence images of the HA-ARTD10-transfected HeLa (Figure 4, ARTD10) and U2OS (Figure 5, ARTD10) cells showed that ARTD10 and GAPDH co-localised into cytoplasmic cell bodies. On the contrary, when the cells were transfected with the inactive mutant HA-ARTD10-G888W only minimal localisation of GAPDH into cytoplasmic cell bodies was seen (Figures 4 and 5, ARTD10-G888W). 


\section{HeLa cells}
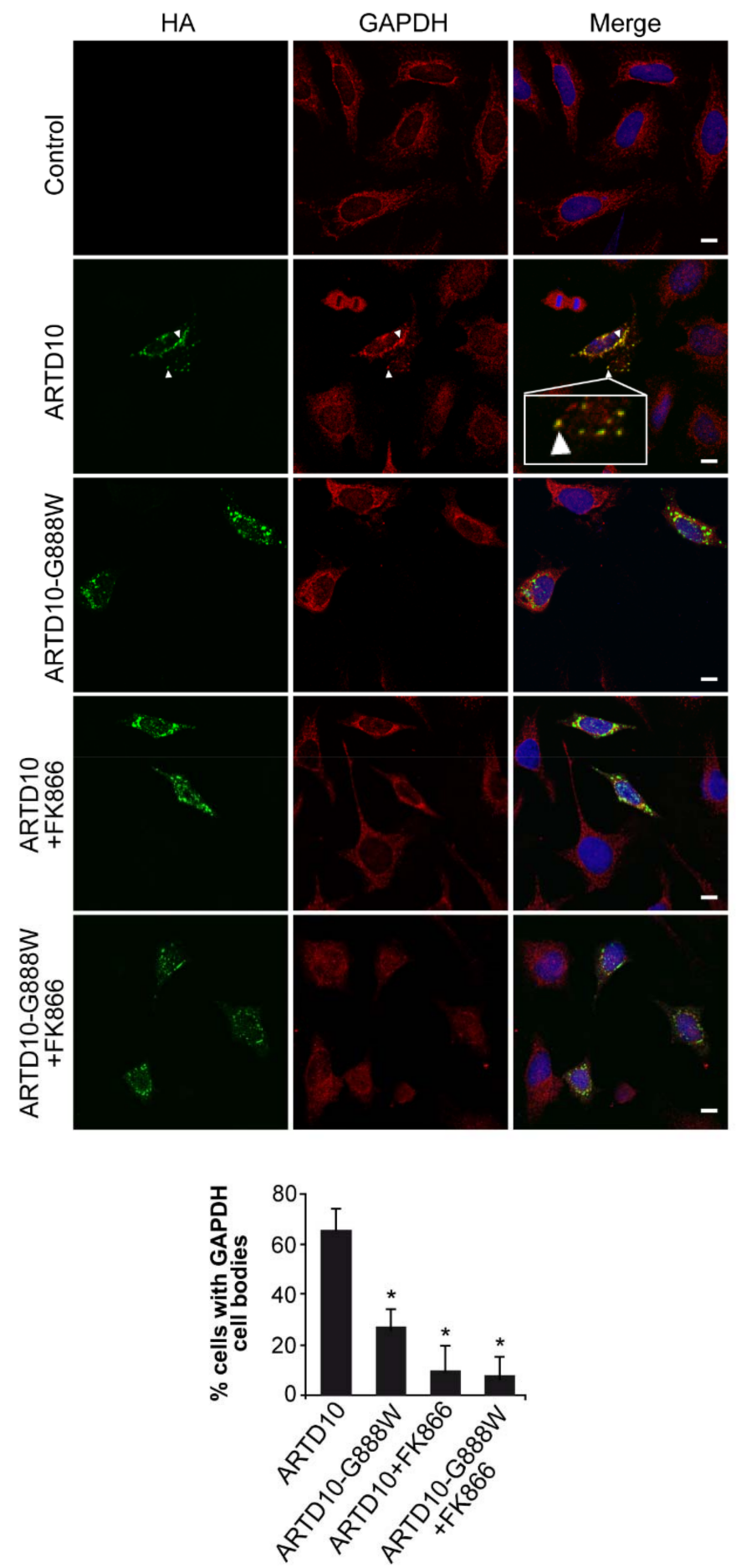

Figure 4. Staining of overexpressed ARTD10/PARP10 and endogenous GAPDH in HeLa cells. Representative immunofluorescence microscopy of HeLa cells that were mock transfected (Control) or were transiently transfected with HA-ARTD10 or HA-ARTD10-G888W, without and with treatment with FK866 (HA-ARTD10 + FK866, HA-ARTD10-G888W + FK866). The cells were stained with anti-HA (HA; green) and anti-GAPDH (GAPDH; red) antibodies, and analysed by immunofluorescence microscopy. The nuclei were stained with DRAQ5. Transfected cells treated with FK866 were incubated for $24 \mathrm{~h}$ with $10 \mathrm{nM}$ FK866. Scale bars, $10 \mu \mathrm{m}$. Quantification of \% ARTD10 cytoplasmic cell bodies positive for GAPDH is shown, with the data expressed as means \pm SD of three independent experiments. ${ }^{*}, p<0.01$. The inset shows the localization of GAPDH in cytoplasmic cell bodies. 

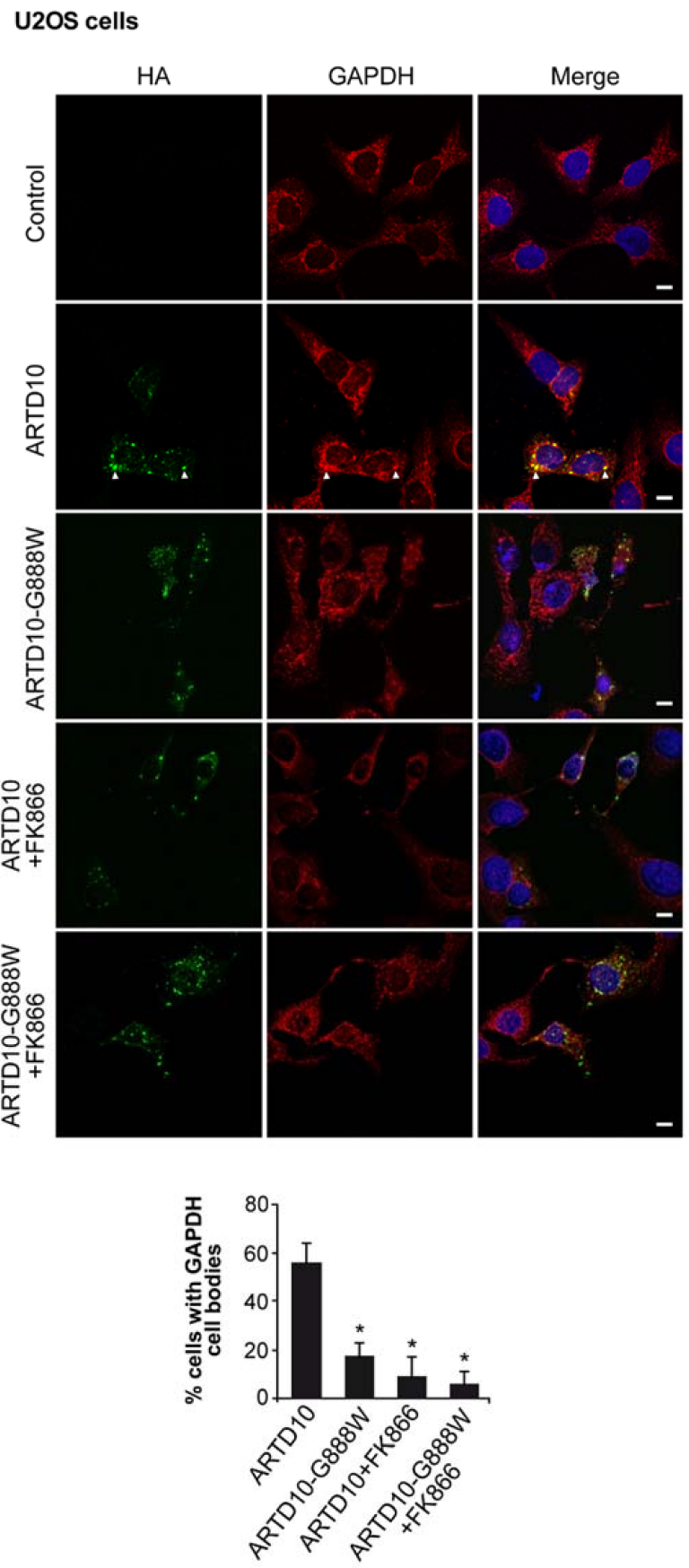

Figure 5. Staining of overexpressed ARTD10/PARP10 and endogenous GAPDH in U2OS cells. Representative immunofluorescence microscopy of U2OS cells that were mock transfected (Control) or were transiently transfected with HA-ARTD10 or HA-ARTD10-G888W, without or with treatment with FK866 (HA-ARTD10 + FK866, HA-ARTD10-G888W+FK866). Scale bars, $10 \mu \mathrm{m}$. See legend to Figure 4 for further details. ${ }^{*}, p<0.01$.

Quantification of the percentage of cell bodies containing GAPDH indicated that $66 \% \pm 9 \%$ and $57 \% \pm 7 \%$ of all of the cell bodies formed in HeLa (Figure 4 ) and U2OS (Figure 5) cells transfected with HA-ARTD10 wt, respectively, were positive for both ARTD10 and GAPDH. The percentage of cell bodies that contained GAPDH decreased to $25 \% \pm 7 \%$ and $17 \% \pm 5 \%$ in HeLa (Figure 4 ) and U2OS (Figure 5) cells transfected with HA-ARTD10-G888W, respectively. These data thus indicate that the catalytic activity of ARTD10 is necessary to recruit GAPDH to these cell bodies. 
This indication was further confirmed in cells that overexpressed the catalytically active ARTD10 (HA-ARTD10 wt) and were treated with FK866, which inhibited the ADP-ribosylation reaction. In the presence of FK866, only around 9\% of the cells bodies formed were positive for both ARTD10 and GAPDH, in both HeLa and U2OS cells. Similar results were obtained when these cells were transfected with PJ34 (not shown).

These data thus indicate that GAPDH is recruited into these cytoplasmic cell bodies in ARTD10 wt overexpressing HeLa cells (Figure 4) and osteosarcoma U2OS cells (Figure 5), and that when the ARTD10 catalytic activity is inhibited, GAPDH localisation resembles that of the control cells, as it disappears from the cytoplasmic cell bodies.

\subsection{The Catalytic Domain of ARTD10 Sequesters GAPDH into Stress Granules}

GAPDH has multiple functions that are both dependent and independent of its role in energy metabolism. GAPDH has been associated with cell proliferation and tumorigenesis, and also with cell death via apoptosis. Previous findings demonstrated that the expression of ARTD10, but not of its catalytically inactive mutant ARTD10-G888W, results in induction of apoptosis and inhibition of cell proliferation [38], leading to the hypothesis that the catalytic activity of ARTD10 is directly involved in these cell processes. However, different ARTD10 proteins containing an intact catalytic domain, but deleted for the N-terminal region (i.e., aa 257-1025 or 407-1025), were unable to induce apoptosis and to inhibit cell proliferation, indicating that the catalytic activity of ARTD10 is required but not sufficient to regulate these cell functions [38]. Thus, to further investigate the involvement of GAPDH in ARTD10-mediated cell function, we used a construct that contains only the catalytic domain of ARTD10 (HA-ARTD10-818-1025, which we refer to here as ARTD10-CD). ARTD10-CD is catalytically active and can modify GAPDH in an in vitro ADP-ribosylation assay (not shown). When the HA-ARTD10-818-1025 construct was transfected into HeLa cells, ARTD10-CD formed cytoplasmic cell bodies that were stained with GST-mAf1521, in line with the presence of ADP-ribosylated proteins in these cell bodies (Figure 6A), and GAPDH co-localised with ARTD10-CD into these cytoplasmic cell bodies (Figure 6B). Moreover, when we analysed the effects of FK866, the co-localisation between ARTD10-CD and GAPDH was lost, although the cell bodies were still present (Figure 6B; the quantification of the percentage of the ARTD10-CD cytoplasmic cell bodies containing GAPDH in the absence or in the presence of FK866 is shown in Figure 6D), as for the full-length ARTD10. Thus, both ARTD10-CD and ARTD10 full-length can modify GAPDH and recruit it into the cell bodies; this is unexpected, considering that the functional consequences of overexpression of ARTD10-CD or ARTD10 full-length are different (for instance, with respect to cell proliferation; as ARTD10, but not ARTD10-CD, inhibits cell proliferation) [38]. This thus led to further investigation of the nature of these cell bodies.

A

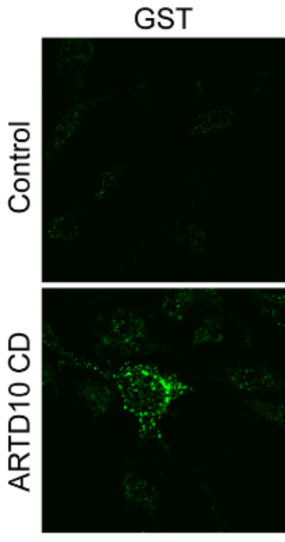

HA

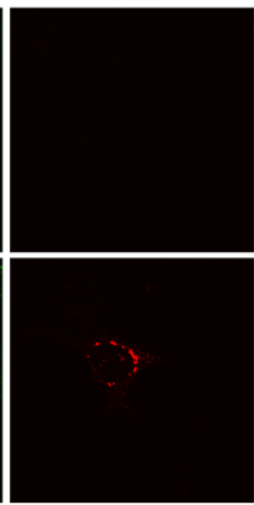

Merge

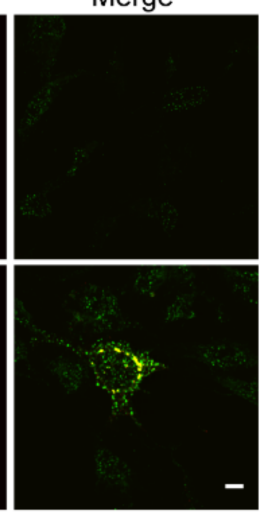

Figure 6. Cont. 


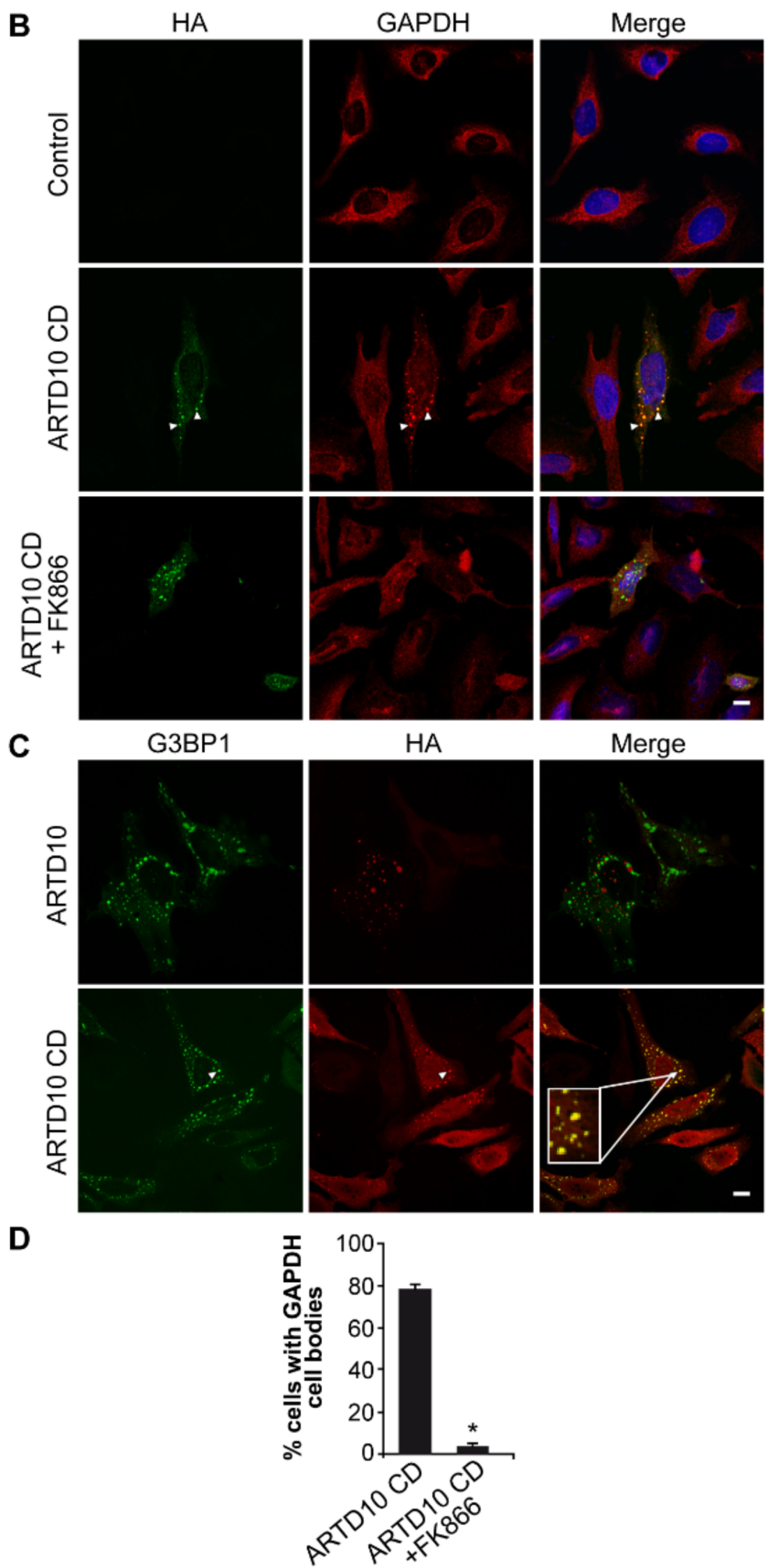

Figure 6. ARTD10/PARP10-CD localises in stress granules. Representative immunofluorescence microscopy of HeLa cells. (A,B) Cells were mock transfected (Control), or were transiently transfected with HA-ARTD10-CD without (A) and with (B) treatment with FK866 (as indicated). (A) The cells were incubated with $m$ Af1521 and stained with anti-GST (GST; green) and anti-HA (HA; red) antibodies (as indicated); (B) The cells were stained with anti-HA (HA; green) and anti-GAPDH (GAPDH; red) antibodies; (C) Cells were transiently transfected with GFP-G3BP1 and with HA-ARTD10 or HA-ARTD10 CD (as indicated). The cells were then stained with anti-HA (HA; red) antibody. Scale bars, $10 \mu \mathrm{m}$. Data are representative of three independent experiments. The inset shows the localization of ARTD10 CD with GFP-G3BP1; (D) Quantification of \% ARTD10-CD cytoplasmic cell bodies positive for GAPDH is shown, with the data expressed as means \pm SD of three independent experiments. ${ }^{*}, p<0.001$. 
Previous studies demonstrated that, differently from ARTD10, other ARTD enzymes, including ARTD5, ARTD7, ARTD12, ARTD13, localise into stress granules and induce stress granules formation when overexpressed in cells [47,48], suggesting that ADP-ribosylation can favor ARTDs recruitment into these distinct proteins aggregates. We thus analysed whether ARTD10-CD can be recruited into stress granules. The immunofluorescence of HeLa cells transiently co-transfected with HA-ARTD10-CD or HA-ARTD10 and Ras-GTPase activating protein SH3 domain binding protein-1 (G3BP1), which induces the formation of stress granules following its overexpression [49], confirmed that these ARTD10-associated cell bodies do not co-localise with stress granules (Figure 6C), and showed that HA-ARTD10-CD co-localises with stress granules (Figure 6C,D). ARTD10-CD can ADP-ribosylate GAPDH, as can ARTD10 wt, and both can sequester GAPDH, although in different structures. This thus indicated that to induce the ARTD10-mediated inhibition of cell proliferation, the formation of the wild type ARTD10-dependent cell bodies is necessary and depends on the N-terminal region. Moreover, as GAPDH is also recruited into structures that are different from those needed to mediate ARTD10-dependent inhibition of cell proliferation, the sequestration of GAPDH, an enzyme that is crucial for cell energy, does not represent per se the mechanism by which ARTD10 inhibits cell proliferation.

\section{Conclusions}

Here, we report that ARTD10/PARP10 interacts with and mono-ADP-ribosylates the glycolytic enzyme GAPDH. The co-localisation of GAPDH and ARTD10 occurs in well-defined cytosolic cell bodies, which we show to be rounded membrane-free structures, using immuno-electron microscopy. FK866, which is a compound known to reduce the cellular NAD ${ }^{+}$levels, and thus to affect the cell energy, can inhibit ARTD10 activity, which results in the release of GAPDH from these cytosolic cell bodies. This indicates that the catalytic activity of ARTD10 is required to recruit GAPDH, but it is not required to induce the formation of these cell bodies. Indeed, as also previously demonstrated [23], catalytically inactive ARTD10 can form these cell bodies. Moreover, their formation is not inhibited by pharmacological inhibition of the catalytic activity of ARTD10, as neither FK866 nor PJ34 affects the formation of these cell bodies. It is known that ARTD10 wt, but not its catalytically inactive mutant, can induce apoptosis and inhibition of cell proliferation, and that these cell functions cannot be induced by an ARTD10 deleted of its N-terminal region, thus indicating that the catalytic activity of ARTD10 is required but not sufficient for these cell functions [36]. We show here that when the catalytic domain of ARTD10 is overexpressed in human cells, the cells form stress granules instead of the cytosolic cell bodies that are formed by full-length ARTD10, and that GAPDH, the protein target of ARTD10, can be recruited into stress granules. Moreover, the dehydrogenase activity of GAPDH appears not to be regulated by its ADP-ribosylation, thus leading us to hypothesise that ADP-ribosylation is important for the recruitment of GAPDH into cell bodies. GAPDH is a potent inducer of apoptosis, which is a cell function that has been attributed to full-length ARTD10, but not to the catalytic domain of ARTD10 alone. As GAPDH is also recruited into structures that are different from those needed to mediate apoptosis, further studies are required to define if and how the sequestration of GAPDH, and probably of additional proteins, into these cell bodies can induce apoptosis.

Supplementary Materials: The following are available online at http://www.mdpi.com/2078-1547/9/1/22/s1.

Author Contributions: E.M., G.F., E.S.S., F.C., H.K., F.A. performed the experiments and prepared the figures, A.S., N.D. performed the experiments, H.K. generated ARTD10 constructs and performed the experiments, B.L. and M.D.G. critically discussed the data and wrote the manuscript.

Funding: We declare the financial support of the Fondazione Cassa di Risparmio della Provincia di Chieti to MDG and of the Deutsche Forschungsgemeinschaft (DFG LU466/16-1) to BL.

Acknowledgments: We thank Gabriele Turacchio for the EM experiments, Elena Fontana for the preparation of figures and Chris Berrie for editorial assistance.

Conflicts of Interest: The authors declare no conflicts of interest. 


\section{Abbreviations}

$\begin{array}{ll}\text { ART } & \text { ADP-ribosyltransferase } \\ \text { GAPDH } & \text { glyceraldehyde-3-phosphate dehydrogenase } \\ \text { CHO cells } & \text { Chinese hamster ovary cells } \\ \text { HeLa cells } & \text { human cervix adenocarcinoma cells } \\ \text { GST } & \text { glutatione S-transferase } \\ \text { PAR } & \text { poly-ADP-ribose } \\ \text { PARP } & \text { PAR polymerase } \\ \text { PARG } & \text { poly (ADP-ribose) glycohydrolase } \\ \text { mART } & \text { mono-ADP-ribosyltransferase } \\ \text { ARH } & \text { ADP-ribosyl hydrolase }\end{array}$

\section{References}

1. Di Girolamo, M.; Dani, N.; Stilla, A.; Corda, D. Physiological relevance of the endogenous mono(ADP-ribosyl)ation of cellular proteins. FEBS J. 2005, 272, 4565-4575. [CrossRef] [PubMed]

2. Dani, N.; Jorge Moura Barbosa, A.; Del Rio, A.; Di Girolamo, M. ADP-Ribosylated Proteins as Old and New Drug Targets for Anticancer Therapy: The Example of ARF6. Curr. Pharm. Des. 2013, 19, 624-633. [CrossRef] [PubMed]

3. Koch-Nolte, F.; Kernstock, S.; Mueller-Dieckmann, C.; Weiss, M.S.; Haag, F. Mammalian ADP-ribosyltransferases and ADP-ribosylhydrolases. Front. Biosci. 2008, 13, 6716-6729. [CrossRef] [PubMed]

4. Hassa, P.O.; Hottiger, M.O. The diverse biological roles of mammalian PARPS, a small but powerful family of poly-ADP-ribose polymerases. Front. Biosci. 2008, 13, 3046-3082. [CrossRef] [PubMed]

5. Gibson, B.A.; Kraus, W.L. New insights into the molecular and cellular functions of poly(ADP-ribose) and PARPs. Nat. Rev. Mol. Cell Biol. 2012, 13, 411-424. [CrossRef] [PubMed]

6. Mangerich, A.; Bürkle, A. Pleiotropic cellular functions of PARP1 in longevity and aging: Genome maintenance meets inflammation. Oxid. Med. Cell. Longev. 2012, 2012, 321653. [CrossRef] [PubMed]

7. Amé, J.C.; Spenlehauer, C.; de Murcia, G. The PARP superfamily. Bioessays 2004, 26, 882-893. [CrossRef] [PubMed]

8. Corda, D.; di Girolamo, M. Functional aspects of protein mono-ADP-ribosylation. EMBO J. 2003, 22, 1953-1958. [CrossRef] [PubMed]

9. Fabrizio, G.; Scarpa, E.S.; Di Girolamo, M. State of the art of protein mono-ADP-ribosylation: Biological role and therapeutic potential. Front. Biosci. 2015, 20, 405-430.

10. Eno, G.H.; Ledford, B.E. ADP-ribosylation of the 78-kDa glucose-regulated protein during nutritional stress. Eur. J. Biochem. 1989, 186, 205-211.

11. Ledford, B.E.; Leno, G.H. ADP-ribosylation of the molecular chaperone GRP78/BiP. Mol. Cell. Biochem. 1994, 138, 141-148. [CrossRef] [PubMed]

12. Chambers, J.E.; Petrova, K.; Tomba, G.; Vendruscolo, M.; Ron, D. ADP ribosylation adapts an ER chaperone response to short-term fluctuations in unfolded protein load. J. Cell Biol. 2012, 198, 371-385. [CrossRef] [PubMed]

13. Fabrizio, G.; Di Paola, S.; Stilla, A.; Giannotta, M.; Ruggiero, C.; Menzel, S.; Koch-Nolte, F.; Sallese, M.; Di Girolamo, M. ARTC1-mediated ADP-ribosylation of GRP78/BiP: A new player in endoplasmic-reticulum stress responses. Cell. Mol. Life Sci. 2015, 72, 1209-1225. [CrossRef] [PubMed]

14. Lupi, R.; Corda, D.; Di Girolamo, M. Endogenous ADP-ribosylation of the G protein beta subunit prevents the inhibition of type 1 adenylyl cyclase. J. Biol. Chem. 2000, 275, 9418-9424. [CrossRef] [PubMed]

15. Lupi, R.; Dani, N.; Dietrich, A.; Marchegiani, A.; Turacchio, S.; Berrie, C.P.; Moss, J.; Gierschik, P.; Corda, D.; Di Girolamo, M. Endogenous mono-ADP-ribosylation of the free Gbetagamma prevents stimulation of phosphoinositide 3 kinase-gamma and phospholipase C- beta2 and Is activated by G-protein-coupled receptors. Biochem. J. 2002, 367, 825-832. [CrossRef] [PubMed]

16. Dani, N.; Mayo, E.; Stilla, A.; Marchegiani, A.; Di Paola, S.; Corda, D.; Di Girolamo, M. Mono-ADP -ribosylation of the G Protein $\beta \gamma$ Dimer Is Modulated by Hormones and Inhibited by Arf6. J. Biol. Chem. 2011, 286, 5995-6005. [CrossRef] [PubMed] 
17. Herrero-Yraola, A.; Bakhit, S.M.; Franke, P.; Weise, C.; Schweiger, M.; Jorcke, D.; Ziegler, M. Regulation of glutamate dehydrogenase by reversible ADP-ribosylation in mitochondria. EMBO J. 2001, 20, 2404-2412. [CrossRef] [PubMed]

18. Haigis, M.C.; Mostoslavsky, R.; Haigis, K.M.; Fahie, K.; Christodoulou, D.C.; Murphy, A.J.; Valenzuela, D.M.; Yancopoulos, G.D.; Karow, M.; Blander, G.; et al. SIRT4 inhibits glutamate dehydrogenase and opposes the effects of calorie restriction in pancreatic beta cells. Cell 2006, 126, 941-954. [CrossRef] [PubMed]

19. Jwa, M.; Chang, P. PARP16 is a tail-anchored endoplasmic reticulum protein required for the PERK- and IRE1alpha-mediated unfolded protein response. Nat. Cell Biol. 2012, 14, 1223-1230. [CrossRef] [PubMed]

20. Di Paola, S.; Micaroni, M.; Di Tullio, G.; Buccione, R.; Di Girolamo, M. PARP16/ARTD15 Is a Novel Endoplasmic-Reticulum-Associated Mono-ADP-ribosyltransferase that interacts with, and modifies Karyopherin- $\beta 1$. PLoS ONE 2012, 7, e37352. [CrossRef] [PubMed]

21. Di Girolamo, M.; Fabrizio, G.; Salvatore Scarpa, E.; Di Paola, S. NAD ${ }^{+}$-Dependent Enzymes at the Endoplasmic Reticulum. Curr. Top. Med. Chem. 2014, 13, 3001-3010. [CrossRef]

22. Feijs, K.L.; Kleine, H.; Braczynski, A.; Forst, A.H.; Herzog, N.; Verheugd, P.; Linzen, U.; Kremmer, E.; Lüscher, B. ARTD10 substrate identification on protein microarrays: Regulation of GSK3beta by mono-ADP-ribosylation. Cell Commun. Signal. 2013, 11, 5. [CrossRef] [PubMed]

23. Rosenthal, F.; Feijs, K.L.; Frugier, E.; Bonalli, M.; Forst, A.H.; Imhof, R.; Winkler, H.C.; Fischer, D.; Caflisch, A.; Hassa, P.O.; Lüscher, B. Macrodomain-containing proteins are new mono-ADP-ribosylhydrolases. Nat. Struct. Mol. Biol. 2013, 20, 502-507. [CrossRef] [PubMed]

24. Yu, M.; Schreek, S.; Cerni, C.; Schamberger, C.; Lesniewicz, K.; Poreba, E.; Vervoorts, J.; Walsemann, G.; Grötzinger, J.; Kremmer, E.; et al. PARP-10, a novel Myc-interacting protein with poly(ADP-ribose) polymerase activity, inhibits transformation. Oncogene 2005, 24, 1982-1993. [CrossRef] [PubMed]

25. Kleine, H.; Herrmann, A.; Lamark, T.; Forst, A.H.; Verheugd, P.; Lüscher-Firzlaff, J.; Lippok, B.; Feijs, K.L.; Herzog, N.; Kremmer, E.; et al. Dynamic subcellular localization of the mono-ADP-ribosyltransferase ARTD10 and interaction with the ubiquitin receptor p62. Cell Commun. Signal. 2012, 10, 28. [CrossRef] [PubMed]

26. Cohen, P.; Frame, S. The renaissance of GSK3. Nat. Rev. Mol. Cell Biol. 2001, 2, 769-776. [CrossRef] [PubMed]

27. Wu, D.; Pan, W. GSK3: A multifaceted kinase in Wnt signaling. Trends Biochem. Sci. 2010, 35, 161-168. [CrossRef] [PubMed]

28. Verheugd, P.; Forst, A.H.; Milke, L.; Herzog, N.; Feijs, K.L.; Kremmer, E.; Kleine, H.; Lüscher, B. Regulation of NF-kappaB signalling by the mono-ADP-ribosyltransferase ARTD10. Nat. Commun. 2013, 4, 1683. [CrossRef] [PubMed]

29. Hayden, M.S.; Ghosh, S. Signaling to NF-kB. Genes Dev. 2004, 18, 2195-2224. [CrossRef] [PubMed]

30. Bruns, G.A.; Gerald, P.S. Human glyceraldehyde-3-phosphate dehydrogenase in man-rodent somatic cell hybrids. Science 1976, 192, 54-56. [CrossRef] [PubMed]

31. Sirover, M.A. New insights into an old protein: The functional diversity of mammalian glyceraldehyde-3-phosphate dehydrogenase. Biochim. Biophys. Acta 1999, 1432, 159-184. [CrossRef]

32. Seidler, N.W. Functional diversity. Adv. Exp. Med. Biol. 2013, 985, 103-147. [PubMed]

33. Du, X.; Matsumura, T.; Edelstein, D.; Rossetti, L.; Zsengellér, Z.; Szabó, C.; Brownlee, M. Inhibition of GAPDH activity by poly(ADP-ribose) polymerase activates three major pathways of hyperglycemic damage in endothelial cells. J. Clin. Investig. 2003, 112, 1049-1057. [CrossRef] [PubMed]

34. Long, C.A.; Boloum, V.; Albadawi, H.; Tsai, S.; Yoo, H.J.; Oklu, R.; Goldman, M.H.; Watkins, M.T. Poly-ADP-ribose-polymerase inhibition ameliorates hind limb ischemia reperfusion injury in a murine model of type 2 diabetes. Ann. Surg. 2013, 258, 1087-1095. [CrossRef] [PubMed]

35. Deveze-Alvarez, M.; García-Soto, J.; Martínez-Cadena, G. Glyceraldehyde-3-phosphate dehydrogenase is negatively regulated by ADP-ribosylation in the fungus Phycomyces blakesleeanus. Microbiology 2001, 147, 2579-2584. [CrossRef] [PubMed]

36. De Matteis, M.A.; Di Girolamo, M.; Colanzi, A.; Pallas, M.; Di Tullio, G.; McDonald, L.J.; Moss, J.; Santini, G.; Bannykh, S.; Corda, D. Stimulation of endogenous ADP-ribosylation by brefeldin A. Proc. Natl. Acad. Sci. USA 1994, 91, 1114-1118. [CrossRef] [PubMed] 
37. Di Girolamo, M.; Silletta, M.G.; De Matteis, M.A.; Braca, A.; Colanzi, A.; Pawlak, D.; Rasenick, M.M.; LuINI, A.L.; Corda, D. Evidence that the 50-kDa substrate of brefeldin A-dependent ADP- ribosylation binds GTP and is modulated by the G-protein beta gamma subunit complex. Proc. Natl. Acad. Sci. USA 1995, 92, 7065-7069. [CrossRef] [PubMed]

38. Herzog, N.; Hartkamp, J.D.; Verheugd, P.; Treude, F.; Forst, A.H.; Feijs, K.L.; Lippok, B.E.; Kremmer, E.; Kleine, H.; Lüscher, B. Caspase-dependent cleavage of the mono-ADP-ribosyltransferase ARTD10 interferes with its pro-apoptotic function. FEBS J. 2013, 280, 1330-1343. [CrossRef] [PubMed]

39. Stilla, A.; Di Paola, S.; Dani, N.; Krebs, C.; Arrizza, A.; Corda, D.; Haag, F.; Koch-Nolte, F.; Di Girolamo, M. Characterisation of a novel glycosylphosphatidylinositol-anchored mono-ADP-ribosyltransferase isoform in ovary cells. Eur. J. Cell Biol. 2011, 90, 665-677. [CrossRef] [PubMed]

40. Dani, N.; Stilla, A.; Marchegiani, A.; Tamburro, A.; Till, S.; Ladurner, A.G.; Corda, D.; Di Girolamo, M. Combining affinity purification by ADP-ribose-binding macro domains with mass spectrometry to define the mammalian ADP-ribosyl proteome. Proc. Natl. Acad. Sci. USA 2009, 106, 4243-4248. [CrossRef] [PubMed]

41. Polishchuk, R.S.; Mironov, A.A. Correlative video light/electron microscopy. Curr. Protoc. Cell Biol. 2001. [CrossRef] [PubMed]

42. Polishchuk, V.P.; Tyvonchuk, T.P.; Rengevich, I.; Beketov, G.V.; Budzanivskaia, I.G.; Bouko, A.L. Use of atomic force microscopy to study the morphology and structure of viruses. Mikrobiol. Zhurnal 2000, 62, 40-43.

43. Kleine, H.; Poreba, E.; Lesniewicz, K.; Hassa, P.O.; Hottiger, M.O.; Litchfield, D.W.; Shilton, B.H.; Lüscher, B. Substrate-assisted catalysis by PARP10 limits its activity to mono-ADP-ribosylation. Mol. Cell 2008, 32, 57-69. [CrossRef] [PubMed]

44. Loesberg, C.; Smets, L.A. Meta-iodobenzylguanidine (MIBG), a novel high-affinity substrate for cholera toxin that interferes with cellular mono(ADP-ribosylation). Biochim. Biophys. Acta 1990, 1037, 92-99. [CrossRef]

45. Yates, S.P.; Taylor, P.L.; Jørgensen, R.; Ferraris, D.; Zhang, J.; Andersen, G.R.; Merrill, A.R. Structure-function analysis of water-soluble inhibitors of the catalytic domain of exotoxin A from Pseudomonas aeruginosa. Biochem. J. 2005, 385, 667-675. [CrossRef] [PubMed]

46. Forst, A.H.; Karlberg, T.; Herzog, N.; Thorsell, A.G.; Gross, A.; Feijs, K.L.; Verheugd, P.; Kursula, P.; Nijmeijer, B.; Kremmer, E.; et al. Recognition of mono-ADP-ribosylated ARTD10 substrates by ARTD8 macrodomains. Structure 2013, 21, 462-475. [CrossRef] [PubMed]

47. Leung, A.K.; Todorova, T.; Ando, Y.; Chang, P. Poly(ADP-ribose) regulates post-transcriptional gene regulation in the cytoplasm. RNA Biol. 2012, 9, 542-548. [CrossRef] [PubMed]

48. Leung, A.K.; Vyas, S.; Rood, J.E.; Bhutkar, A.; Sharp, P.A.; Chang, P. Poly(ADP-ribose) regulates stress responses and microRNA activity in the cytoplasm. Mol. Cell 2011, 42, 489-499. [CrossRef] [PubMed]

49. Isabelle, M.; Gagné, J.P.; Gallouzi, I.E.; Poirier, G.G. Quantitative proteomics and dynamic imaging reveal that G3BP-mediated stress granule assembly is poly(ADP-ribose)-dependent following exposure to MNNG-induced DNA alkylation. J. Cell Sci. 2012, 125, 4555-4566. [CrossRef] [PubMed] 